\title{
Phyllaemblicin B inhibits Coxsackie Virus B3 induced apoptosis and myocarditis
}

Wang Ya-Feng ${ }^{1,2}$,Wang Xiao-Yan ${ }^{1,2}$, Ren Zhe ${ }^{1,2}$,Qian Chui-Wen ${ }^{1,2}$,Li Yi-Cheng ${ }^{1,2}$, Kaio Kitazato ${ }^{3}$,Wang Qing-Duan ${ }^{4}$,Zhang Yan $^{4}$,Zheng Li-Yun ${ }^{4}$,Jiang Jin-Hua ${ }^{4}$, Yang Chong-Ren ${ }^{5}$, Liu Qing ${ }^{5}$, Zhang Ying-Jun ${ }^{5}$,Wang Yi-Fei ${ }^{1,2 *}$

( ${ }^{1}$ Jinan University, Guangdong, Guangzhou, 510630,China; ${ }^{2}$ National Engineering Research Center of Genetic Medicine, Guangdong, Guangzhou, 510630,China; ${ }^{3}$ Laboratory of Molecular Biology of Infectious Agents, Department of Molecular Microbiology and Immunology, Graduate School of Biomedical Sciences, Nagasaki University, Nagasaki, Japan; ${ }^{4}$ Henan Institute of Medical Sciences,Henan,Zhengzhou,450000,China, ${ }^{5}$ Kunming Institute of Botany, the Chinese Academy of Sciences,Yunnan,Kunming,650204,China.)

\section{Abstract}

Coxsackie virus B3 (CVB3) is believed to be a major contributor to viral myocarditis since virus-associated apoptosis plays a role in the pathogenesis of experimental myocarditis. In this study, we investigated the in vitro and in vivo antiviral activities of Phyllaemblicin B, the main ellagitannin compound isolated from Phyllanthus emblica, a Chinese herb medicine, against CVB3. Herein we report Phyllaemblicin B inhibited CVB3-mediated cytopathic effects on HeLa cells with an $\mathrm{IC}_{50}$ value of $7.75 \pm 0.15 \mu \mathrm{g} / \mathrm{mL}$. In an in vivo assay, treatment with $12 \mathrm{mg} \cdot \mathrm{kg}^{-1} \cdot \mathrm{d}^{-1}$ Phyllaemblicin B reduced cardiac CVB3 titers, decreased the activities of $\mathrm{LDH}$ and $\mathrm{CK}$ in murine serum, and alleviated pathological damages of cardiac muscle in myocarditic mice. Moreover, Phyllaemblicin B clearly inhibited CVB3-associated apoptosis effects both in vitro and in vivo. These results show that Phyllaemblicin B exerts significant antiviral activities against CVB3. Therefore, Phyllaemblicin B may represent a potential therapeutic agent for viral myocarditis.

\footnotetext{
* Correspondence: Wang Yi-Fei; Zhang Ying-Jun; Kaio Kitazato. Jinan University, Guangdong, Guangzhou, 510630,China;.Fax:86-20-85223426; E-mail: twang-yf@163.com
} 
Keywords: Coxsackie virus B3; Viral myocarditis; Phyllaemblicin B; Antiviral effect; Apoptosis

\section{Introduction}

Coxsackie virus B3 (CVB3) is a member of the genus Enterovirus of the Picornaviridae family that contains a single-stranded, positive-sense RNA genome. It is a cardiotropic virus known to induce viral myocarditis (Kuhl et al. 2005) in children and young people, which is a common cause of acute heart failure and dilated cardiomyopathy (DCM). Unrecognized viral myocarditis develops into DCM in two-thirds of the patients. Several studies suggest that not only viral infection of the myocardium itself but the associated inflammatory responses are determinants of the virus-associated myocardial damage (Chow et al. 1992; McManus et al. 1993; Huber et al. 1999; Henke et al. 1995; Antoniak et al. 2008). However, until now, the mechanisms detailing how CVB3 causes myocarditis are not well characterized nor are there virus-specific preventive or therapeutic procedures available to protect humans against CVB3-induced heart diseases.

Apoptosis, programmed cell death, is a distinct type of cell death, which is characterized by a series of typical morphological features (Kerr et al. 1972) and regulated by several factors. Previous studies show that apoptotic events occur frequently during CVB3 infections under in vitro as well as in vivo conditions (Feuer et al. 2003; Saraste et al. 2003; Yuan et al. 2003; Carthy et al. 1998). Recently, it has been demonstrated that one hallmark of CVB3-induced pathogenesis is apoptosis; hence, the activation of apoptotic pathways during CVB3 infection is of a growing interest (Cunningham et al. 2003). The mitochondria-mediated pathway is commonly believed to 
be associated with apoptosis induced by CVB3. Mitochondria have increasingly become recognized as central regulators of caspase activation during CVB3 infection. Caspase activation (Martin et al. 2007) and mitochondrial release of cytochrome c (Carthy et al. 2003) may be an important early event in CVB3 infection. Bcl-2 is an antiapoptotic molecule which regulates mitochondrial permeability and release of cytochrome c into the cytosol. Once cytochrome $\mathrm{c}$ is released, caspase is activated and apoptosis is triggered via the mitochondria-mediated pathway ( $\mathrm{Si}$ et al. 2005). However, although some pathogenic pathways of CVB3 are well documented, details regarding CVB3 involvement in the apoptotic processes remain unclear.

Phyllaemblicin B is the main ellagitannin compound isolated from the roots of Phyllanthus emblica L. (Euphorbiaceae), which is a shrub or tree that grows in subtropical and tropical areas of the People's Republic of China, India, Indonesia, and the Malay Peninsula (Zhang et al. 2001). It is widely used in many local traditional medicinal systems, such as Chinese herbal medicine, Tibetan medicine, and Ayurvedic medicine for its anti-inflammatory and antipyretic effects. Minority groups living in the southwest of China use the roots of P. emblica for the treatment of eczema, and in Nepal it is used as an astringent and hematostatic agent (Xia et al. 1997). Recently, anti-CVB3 activity of Phyllaemblicin B has shown by our group in order to determine its possible pharmacological mechanism, in this study, we further investigated its activities against CVB3 in vitro and in vivo.

\section{Materials and methods}

\section{Agents}

Phyllaemblicin B was obtained from the Laboratory of Phytochemistry, Kunming 
Institute of Botany, Chinese Academy of Sciences, (China) (Zhang et al. 2000). The $\begin{array}{llllll}\text { chemical structure } & \text { is } & \text { shown } & \text { in } & \text { Figure } & 1 .\end{array}$ 3-[4,5-Dimethyl-2-thiazolyl]-2,5-diphenyl-2-tetrazolium bromide (MTT) was purchased from Sigma. Ribavirin (injection, $100 \mathrm{mg} / \mathrm{mL}$ ) was purchased from the Guangzhou Shiqiao Parmaceutical Group Corporation (lot no. 0705072). Twice distilled deionized water was used throughout the experiments.

\section{Virus and cell cultures}

Coxsackie virus B3 Nancy strain, which was generously provided by the Wuhan Institute of Virology, Chinese Academy of Sciences, was propagated in HeLa cell monolayers and stored at $-80{ }^{\circ} \mathrm{C}$ until use. Viral titers were determined by $\mathrm{TCID}_{50}$ assays, and infections with CVB3 were performed at 100 TCID $_{50}$. HeLa cells were obtained from the American Type Culture Collection and routinely grown in complete medium (Dulbecco's modified Eagle's medium [DMEM; Gibco] supplemented with 10\% heat-inactivated newborn calf serum, $0.1 \%$ L-glutamine, $100 \mathrm{U} / \mathrm{mL}$ penicillin, and 0.1 $\mathrm{mg} / \mathrm{mL}$ streptomycin) at $37{ }^{\circ} \mathrm{C}$ in a humid atmosphere with $5 \% \mathrm{CO}_{2}$. The test medium used for the cytotoxic assay as well as for antiviral assays contained $2 \%$ of the calf serum.

\section{Animals}

BALB/c mice (4 weeks of age, between 14 to $16 \mathrm{~g}$, male) were purchased and maintained at the Experimental Animal Center, Zhengzhou University (clean grade, certificate no. 0009706). They were housed in constant conditions at a temperature of 23 $\pm 1{ }^{\circ} \mathrm{C}$, a humidity level of $40 \pm 5 \%$, and on a 12-h light/12-h dark cycle. They had free access to pellet food and tap water. 


\section{In vitro antiviral activity experiments}

\subsection{Determination of cytotoxicity}

The cytotoxicity of the compound was determined using a quantitative colorimetric MTT [(3-(4, 5- dimethylthiazol-2-yl)-2, 5-diphenyl tetrazolium bromide)] assay (Mosmann, 1983). Briefly, HeLa cells were seeded in 96-well plates and grown to monolayers. After removal of the growth medium, serial two-fold dilutions of the compound in $100 \mu \mathrm{L}$ test medium were added. The plates were incubated at $37^{\circ} \mathrm{C}$ and checked daily by light microscopy. After $48 \mathrm{~h}$ of incubation, $20 \mu \mathrm{L}$ MTT $(0.5 \mathrm{mg} / \mathrm{mL})$ was added to each well and allowed to react for $4 \mathrm{~h}$. After removal of supernatant, $100 \mu \mathrm{L}$ of DMSO were added to each well. Plates were incubated at room temperature for $30 \mathrm{~min}$ and the optical density (OD) was measured at the dual wavelengths of 570 and $630 \mathrm{~nm}$. The $50 \%$ cytotoxic concentration $\left(\mathrm{CC}_{50}\right)$ was defined as the concentration of compound required to reduce the viability of untreated cell cultures by $50 \%$. The mean dose-response curve of at least three tests was used to calculate the $\mathrm{CC}_{50}$.

\subsection{Antiviral activity}

HeLa cells were grown in 96-well plates and were allowed to form monolayers. Fifty microliters of viral suspensions containing $100 \mathrm{TCID}_{50}$ of the virus stock and an equal volume of medium containing various concentrations of the test compound at doses below the $\mathrm{CC}_{50}$ were added to each well. Non-infected and infected cells without the test compound served as a cell and virus controls, respectively. Ribavirin (RBV) was used as a reference compound. When virus control cells showed the maximum cytopathic effect, the antiviral effect was determined using the MTT assay following the protocol described above (Determination of cytotoxicity). All data were analyzed and the half-maximal 
inhibitory concentration $\left(\mathrm{IC}_{50}\right)$ was calculated. The therapeutic index (TI) was determined from $\mathrm{CC}_{50} / \mathrm{IC}_{50}$.

\subsection{Fluorescence activated cell sorting (FACS) for detection of apoptosis}

Apoptosis was detected by using Annexin V/ propidium iodide (PI) staining. In brief, HeLa cells infected with CVB3 were treated with the test compound for $24 \mathrm{~h}$, according to the $\left(\mathrm{IC}_{50}\right)$. After removing the supernatant, cells were digested by trypsin $(0.05 \%)$ and washed three times with ice-cold phosphate-buffered saline (PBS). The cells were re-suspended and stained with Annexin V-FITC and PI. The fresh samples were analyzed for apoptosis by FACS.

\subsection{Two-dimensional gel electrophoresis (2-DE)}

Treated $(25 \mu \mathrm{g} / \mathrm{mL}$ Phyllaemblicin B + CVB3) and control (DMEM + CVB3) samples were harvested, washed three times with ice-cold wash buffer $(10 \mu \mathrm{M}$ Tris- $\mathrm{HCl}, 250 \mu \mathrm{M}$ sucrose, $\mathrm{pH}$ 7.0), and lysed with a buffer containing 8 M Urea, 4\% CHAPS, $2 \%$ IPG buffer, and $0.2 \mathrm{mg} / \mathrm{mL}$ PMSF for 30 minutes at $4{ }^{\circ} \mathrm{C}$ with occasional vortex mixing. The insoluble material was removed by centrifugation $(12,000 \times \mathrm{g})$ for $30 \mathrm{~min}$ at $4{ }^{\circ} \mathrm{C}$ and the protein concentrations were determined by the Bradford assay. Samples were frozen at $-80{ }^{\circ} \mathrm{C}$, and thawed immediately before use. In the first dimension (isoelectric focusing) total proteins $(130 \mu \mathrm{g})$ were mixed with up to $250 \mu \mathrm{L}$ of rehydration solution (8 M urea, 2\% CHAPS, $20 \mathrm{mM}$ DTT and 0.5\% IPG buffer) and separated by isoelectric focusing (IEF) using Immobilized pH Gradient (IPG) drystrips with a $\mathrm{pH}$ range of 3-10 on an Ettan IPGphor 3 (General Electric Company, USA) with a programmed voltage gradient. Following IEF separation, gel strips were subjected to a two-step equilibration and resolved by $12.5 \%$ SDS-PAGE in the second dimension. Gels were stained with silver 
nitrate overnight and gel images were scanned and analyzed using Image Master 2D Platinum 6.0 (GE Healthcare, Uppsala, Sweden). The quantity of each spot in a gel was normalized as a percentage of the total quantity of all spots in that gel and used for comparison. Only those protein spots that showed consistent and significant differences (more than 1.5 -fold) were selected for analysis by mass spectrometry (MS).

\subsection{Protein digestion}

For MS analysis, protein spots from polyacrylamide gels were excised, rinsed twice with deionized water $\left(\mathrm{ddH}_{2} \mathrm{O}\right)$, destained in a $1: 1$ solution of $30 \mathrm{mM}$ potassium ferricyanide, and then equilibrated in $50 \mathrm{mM}$ ammonium bicarbonate to $\mathrm{pH}$ 8.0. After hydrating with acetonitrile and drying in a SpeedVac, gel spots were rehydrated in a minimal volume of sequencing grade porcine trypsin solution $(20 \mu \mathrm{g} / \mathrm{mL}$ in $25 \mathrm{mM}$ $\mathrm{NH}_{4} \mathrm{HCO}_{3}$ ) and incubated at $37{ }^{\circ} \mathrm{C}$ overnight. Supernatants were extracted once with extraction buffer (67\% acetonitrile containing $1 \%$ trifluoroacetic acid). The peptide extracted and the supernatant of the gel spot was combined and completely dried. Protein digested extracts (tryptic peptides) were resuspended in $5 \mu \mathrm{L}$ of $0.1 \%$ trifluoroacetic acid, then the peptide samples were mixed (1:1 ratio) with a saturated solution of $\alpha$-cyano-4-hydroxy-trans-cinnamic acid in $50 \%$ acetonitrile containing $0.1 \%$ trifluoroacetic acid. Aliquots $(0.8 \mu \mathrm{L})$ were spotted onto a stainless steel sample target plate.

\subsection{MALDI-TOF/TOF analysis}

Peptide mass spectra was obtained on an Applied Biosystem Sciex 4800 MALDITOF/TOF mass spectrometer. Data were acquired in a positive MS reflector using a CalMix5 standard to calibrate the instrument (ABI4700 Calibration Mixture). Mass 
spectra was obtained from each sample spot by accumulation of 600-800 laser shots in a 900-4000 mass range. For MS/MS spectra, the five most abundant precursor ions per sample were selected for subsequent fragmentation and 900-1200 laser shots were accumulated per precursor ion. The criterion for precursor selection was a minimum $\mathrm{S} / \mathrm{N}$ of 50. Both the MS and MS/MS spectra for each spot were combined and submitted to the MASCOT search engine (V2.1, Matrix Science, U.K.) using GPS Explorer software (V3.6, Applied Biosystems) and were scanned against the following parameters: IPI Human database (V3.36), Homo sapiens (human) taxonomy, tryptic digests, one missed cleavage site, partial modification of cysteine (carboamidomethylated) and methionine (oxidized), no fixed modifications, MS tolerance of 30-60 ppm, MS/MS tolerance of 0.2-0.3 Da. Known contaminant ions (keratin) were excluded. A total of 69,012 sequences and 29,002,682 residues in the database were actually searched. MASCOT protein scores $>61$ (based on combined MS and MS/MS spectra) were considered statistically significant $(p<0.05)$.

\subsection{RNA isolation and real-time RT-PCR}

Preparation and isolation of total RNA from cell samples were performed using TRIzol Reagent (Invitrogen, USA). One microgram of total RNA was reverse transcribed to yield single-stranded cDNA by RevertAid ${ }^{\mathrm{TM}}$ M-MuLV Reverse Transcriptase (Fermentas), oligo(dT) ${ }_{18}$ (Invitrogen) and a pool of dNTPs (TaKaRa). cDNAs obtained from reverse transcription were stored at $-20^{\circ} \mathrm{C}$. For real-time PCR, SYBR Premix Ex Taq ${ }^{\mathrm{TM}}(\mathrm{TaKaRa})$ was used according to the manufacturer's protocol. A set of three genes (encoding proteins caspase-3, bcl-2, and GAPDH) were analyzed for their expression patterns. Primer pairs were designed using Primer Premier 5 and are listed as following: caspase-3, 
forward primer 5'-TGAGGCGGTTGTAGAAGAG-3'; $\quad$ reverse primer 5'-TAATGAGAATGGGGGAAGA-3', bcl-2, forward primer 5'-GATTGATGGGATCGTTGCCTTA-3'; $\quad$ reverse primer 5'-CCTTGGCATGAGATGCAGGA-3', GAPDH, forward primer 5'-AACGGATTTGGTCGTATTGGG-3'; ${ }^{\prime}$ reverse 5'TCGCTCCTGGAAGATGGTGAT -3'. Each real-time PCR reaction was performed for 40 cycles at $95{ }^{\circ} \mathrm{C}$ for $1 \mathrm{~min}, 95{ }^{\circ} \mathrm{C}$ for $15 \mathrm{~s}, 58{ }^{\circ} \mathrm{C}$ for $15 \mathrm{~s}$, and $72{ }^{\circ} \mathrm{C}$ for $40 \mathrm{~s}$. The reactions were carried out in an ABI Prism 7000 Sequence Detection System (Applied Biosystems). The relative expression levels of the target genes were normalized to the housekeeping gene GAPDH and were calculated using the formula (Livak and Schmittgen, 2001): Rel Exp $=2^{(-\Delta \Delta \mathrm{CT})}=2^{-[(\text {CTsample-CThousekeepinggene)-(CTvirus-CThousekeepinggene) }]}$. Each real-time PCR reaction was performed in triplicate.

\subsection{Western blot}

Cell samples, either untreated or treated with different experimental reagents, were harvested, rinsed twice in ice-cold PBS, and kept on ice for 30 minutes in cell lysis buffer (Beyotime Biotechnology, China) with $1 \mathrm{mM}$ PMSF (CHILE, USA) while agitating constantly. The lysates were centrifuged at $12,000 \times \mathrm{g}$ at $4{ }^{\circ} \mathrm{C}$ for $15 \mathrm{~min}$ and the protein concentration of the supernatant was measured using the BCA (bicinchoninic acid) protein assay kit (Beyotime Biotechnology, China). Samples were either applied immediately or stored at $-80{ }^{\circ} \mathrm{C}$ until use. Equal amounts of protein $(50 \mu \mathrm{g})$ were loaded on a $12 \%$ SDS-polyacrylamide gel for electrophoresis and subsequently transferred to PVDF membranes (Millipore, USA). Membranes were blocked at room temperature for 2 h with a $5 \%$ nonfat dry milk solution containing $0.1 \%$ Tween 20 and incubated at $4{ }^{\circ} \mathrm{C}$ 
overnight with antibodies against rabbit caspase-3 (ABZOOM, USA), bcl-2 (EPITOMICS, USA) and mouse $\beta$-actin (ProteinTech Group, Inc, USA). After three 10-min washes in TBST, the membranes were incubated for $2 \mathrm{~h}$ at room temperature with a secondary antibody in blocking solution. Protein bands were visualized with an enhanced chemiluminescence (ECL) detection system according to the manufacturer's protocol (Paragon Biotech, China). Any differences in protein loading were normalized to corresponding levels of $\beta$-actin control.

\section{In vivo antiviral activity experiments}

\subsection{Experimental design and antiviral therapy}

In this study, 90 male BALB/c mice of 4-6 weeks in age were randomly divided into six groups of fifteen each. Of which, 75 mice were infected by intraperitoneal injection with $0.2 \mathrm{~mL}$ physiological saline containing 100TCID $_{50}$ of purified CVB3, 15 mice were not infected and used as normal controls. Sixty inoculated mice were injected intravenously with Phyllaemblicin B at a dose of $12 \mathrm{mg} \cdot \mathrm{kg}^{-1} \cdot \mathrm{d}^{-1}, 8 \mathrm{mg} \cdot \mathrm{kg}^{-1} \cdot \mathrm{d}^{-1}, 4$ $\mathrm{mg} \cdot \mathrm{kg}^{-1} \cdot \mathrm{d}^{-1}$, or with Ribavirin (RBV) at a dose of $125 \mathrm{mg} \cdot \mathrm{kg}^{-1} \cdot \mathrm{d}^{-1}$ daily for seven days and observed carefully. Fifteen of the inoculated mice were given $0.9 \%$ physiological saline by intravenous injection daily and used as infected controls. Mice were sacrificed on day eight post-infection. Blood was collected from the eye sockets and separated into serum in order to detect the activities of several biochemical markers, such as creatine kinase (CK) and lactic dehydrogenase (LDH) by using commercially available kits (Nanjing Jiancheng Biology Engineer Institute, China) according to the manufacturer's protocol to identify myocardial injury. The heart was divided into two parts, one part was homogenized in DMEM to determine virus titers by $\mathrm{TCID}_{50}$ assays, and the other part 
was fixed for further histological, immunohistochemical, and terminal transferase-mediated DNA nick end-labeling (TUNEL) examinations.

\subsection{Virus titers of the heart}

Mice were sacrificed eight days post-infection. The hearts were removed, washed with physiological saline, and homogenized aseptically in DMEM. Homogenates were centrifuged at $2000 \times \mathrm{g}$ for $10 \mathrm{~min}$ at $4{ }^{\circ} \mathrm{C}$. Virus titers were measured in 10 -fold serial dilutions of the supernatant in DMEM by TCID $_{50}$ assays in HeLa cells.

\subsection{Histology}

Histology was performed to examine myocardial injury and inflammatory lesions. Mice were sacrificed eight days post-infection. Hearts were dissected from the mice, fixed in $10 \%$ formalin solution, embedded in paraffin, sectioned serially to a thickness of $3 \mu \mathrm{m}$, and stained with hematoxylin-eosin (HE). HE-stained sections were blindly and independently examined under a light microscope for signs of myocarditis. Photographs were taken with a camera.

\subsection{Measurement of apoptosis}

Cells undergoing apoptosis were evaluated by TUNEL assays using the DeadEnd ${ }^{\mathrm{TM}}$ Fluorometric TUNEL System (Promega, USA). In brief, deparaffinized myocardial sections were digested with proteinase-K to expose the DNA. Any DNA strand breaks were labeled using terminal transferase with ddUTP molecules conjugated to alkaline phosphatase and visualized immunohistochemically. The TUNEL-positive apoptotic cardiomyocyte nuclei were examined under a fluorescence microscope using a standard fluorescein filter set at $520 \pm 20 \mathrm{~nm}$.

\subsection{Immunohistochemistry}


Three-micrometer serial sections were cut from paraffin-embedded tissue blocks, deparaffinized through a graded series of alcohol, and heat-treated in a microwave oven for citrate antigen retrieval. Having been blocked in $5 \%$ bovine serum albumin (BSA) for $30 \mathrm{~min}$, the sections were incubated at $4{ }^{\circ} \mathrm{C}$ overnight with the primary antibody against rabbit caspase-3 or bcl-2. After washing three times with PBS, slides were incubated with the second antibody. Bound immunoglobulins were detected by the $\mathrm{ABC}$ method using commercially available kits (Wuhan Boster Biological Technology, China).

\section{Statistical analysis}

Quantitative results were given as mean $\pm \mathrm{SD}$ and statistical significance were determined by one-way analysis of the $t$ test. For all tests, $P$ values of less than 0.05 were considered statistically significant. Statistical analyses were carried out using SPSS 9.0 software (SPSS Inc., Chicago, IL, USA).

\section{Results}

\section{Phyllaemblicin B has potent activity against CVB3 replication in vitro}

The cytotoxicity and antiviral activity of Phyllaemblicin B against CVB3 were examined in HeLa cells, and the results are presented in Table 1. The $\mathrm{TC}_{50}$ and $\mathrm{IC}_{50}$ of Phyllaemblicin B were $50.30 \pm 1.59 \mu \mathrm{g} / \mathrm{mL}$ and $7.75 \pm 0.15 \mu \mathrm{g} / \mathrm{mL}$, respectively. In antivirus assay, the therapeutic index (TI) of Phyllaemblicin B and Ribavirin were $6.49 \pm 0.09$ and $3.85 \pm 0.11$, respectively.

\section{Phyllaemblicin B can strongly inhibit CVB3-induced apoptosis in} vitro

HeLa cells infected with CVB3 were incubated with $25 \mu \mathrm{g} / \mathrm{mL}$ Phyllaemblicin B and $125 \mu \mathrm{g} / \mathrm{mL}$ Ribavirin respectively, stained with Annexin V/PI, and harvested to evaluate 
apoptotic changes. The results are summarized in Fig. 2. The apoptosis rate in cells treated with Phyllaemblicin B and Ribavirin were significantly lower than the infected controls, suggesting that Phyllaemblicin B can strongly inhibit apoptosis induced by CVB3.

\section{Proteome analysis CVB3-infection cells with or without}

\section{Phyllaemblicin B treatment}

The protein expression profiles of treated and control groups in the context of CVB3 infection were analyzed by 2-DE and MALDI-TOF/TOF MS (Fig. 3A). More than $90 \%$ of overlapped protein spots were achieved in parallel gels from the same group, indicating that the spots used for differential analysis was reproducible. Fifty proteins showed altered expression compared with the infected control group, of which three

proteins were identified as having $>2$-flod change. As shown in Table 2, MALDI-TOF/TOF MS analysis identified each of the three proteins. After Phyllaemblicin B treatment, proteins SDHA, GPX1 and TRAP1 were significantly upregulated (Fig. 3B).

\section{Phyllaemblicin B can significantly alter transcription levels of apoptosis-related genes in vitro}

Two apoptosis-related genes, caspase- 3 and bcl-2 were chosen for quantitative analysis of their expression levels in the treated and control groups using a real-time RT-PCR. The expression level of each gene was normalized to the house keeping gene, GAPDH., Treated levels were compared against those of controls using the relative quantification $\left(2^{-\Delta \Delta \mathrm{CT}}\right)$ method. As shown in Fig. 4 , the caspase-3 and bcl-2 values of the treated groups were 0.13 - and 2.77-fold, respectively, of the GAPDH transcript control. Phyllaemblicin 
B reduced the amount of caspase- 3 mRNA and markedly increased the bcl- 2 mRNA level in treated groups in contrast to infected control groups. The quantitative PCR data were corroborated by Western blot analysis, expression of caspase-3 was significantly reduced upon treatment with Phyllaemblicin B, while bcl-2 expression was significantly elevated when compared with infected controls (Fig. 5). These results suggest that apoptosis induced by CVB3 could be inhibited strongly by Phyllaemblicin B.

\section{Effects of Phyllaemblicin B on the level of serum enzymes LDH and CK in CVB3-infected mice}

The activities of lactate dehydrogenase (LDH) and Creatine Kinase (CK) in mouse serum were significantly enhanced at eight days after CVB3 infection. In the treated group, Phyllaemblicin B and Ribavirin resulted in an obvious decrease in the activities of LDH and CK compared with the infected group. The results are shown in Fig. 6.

\section{Effects of Phyllaemblicin B on CVB3 replication in infected mice}

Virus titers in hearts of CVB3-infected mice peaked on day eight post-infection. Wheras, the virus titers of Phyllaemblicin B-treated groups and Ribavirin-treated guoups were much lower than those of the untreated-control groups (Fig. 7). These results indicate that Phyllaemblicin B has potent activity against CVB3 replication in infected mice.

\section{Effects of Phyllaemblicin B on CVB3-induced myocarditis in mice}

Infection with the CVB3 caused severe myocarditis in mice, but death and weight loss did not occur. The pathological process was often accompanied by mononuclear cell inflammation and the appearance of multiple foci in necrotic cardiomyocyte (Fig. 8B), in contrast to the normal group, which the structural arrangement of myocardium of was 
clear, i.e., the cell nucleolus was obvious and the cytoplasm was enriched (Fig. 8A). In groups treated with Phyllaemblicin B or Ribavirin, the damage to the myocardium was relieved and the area of necrosis and inflammatory infiltrates was significantly decreased compared with non-treated, infected animals (Fig. 8C-F).

\section{Phyllaemblicin B can significantly reduce CVB3-induced apoptosis of cardiomyocytes in infected mice}

In this study, we identified apoptotic cells in the myocardium by using fluorescent labeling of DNA strand breaks. There were very few apoptotic cardiomyocyte nuclei in normal groups. But in infected controls, we identified many more TUNEL-positive cells throughout the myocardium. In the Phyllaemblicin B-treated groups $\left(12 \mathrm{mg} \cdot \mathrm{kg}^{-1} \cdot \mathrm{d}^{-1}\right)$, the amount of TUNEL-positive cardiomyocyte was decreased significantly (Fig. 9). The heart tissues were also analyzed immunohistochemically to determine the expression of apoptosis-related proteins. As shown in Fig. 10, treatment with Phyllaemblicin B notably decreased the expression levels of caspase- 3 while increasing bcl-2 expression compared with non-treated, infected groups.

\section{Discussion}

Phyllaemblicin B is the main ellagitannin compound isolated from the roots of Phyllanthus emblica L. (Euphorbiaceae) and its biological effects have not been widely studied. In this study, the first time to demonstrate that Phyllaemblicin B has potent anti-CVB3 activities in vitro and in vivo and can significantly inhibit CVB3-induced apoptosis and myocarditis.

It is well known that viral myocarditis is mainly caused by coxsackie virus B3. Usually it is a mild disease, but if the virus persists after a clinically silent myocarditis, it will 
eventually lead to irreversible myocardial injury and progressive cardiac dysfunction. Although the exact pathogenic mechanism of viral myocarditis is still unclear, the damage in myocytes induced by CVB3 are suspected to be caused by autoimmune inflammation (Antoniak et al. 2008; Cihakova and Rose, 2008), direct viral cytotoxicities (Kearney et al. 2001), and virus-induced apoptosis (Yuan et al. 2003; Martin et al. 2007; Carthy et al. 2003). In the clinic, immunosuppressive agents (azathioprine, prednisone, and cyclosporine), intravenous immunoglobulin (IVIG), and antiviral agents (interferon, pleconaril, and acyclovir), have been used for the treatment of the disease (Brunetti and DeSantis, 2008). However, most of these are symptomatic treatment since specific agents have not been well established for patients with viral myocarditis of dilated cardiomyopathy. Recently, increasingly more active ingredients isolated from traditional Chinese medicines have been shown to have antiviral activities against CVB3 (Zhu et al. 2009; Wang et al. 2009; Su et al. 2006).

To detect whether the mouse was infected with CVB3, the most specific features are the activities of biochemical markers, virus titers of the organs and the histology changes of the heart. Death and weight loss are not the overt signs of infection. In this study, we treated the $\mathrm{BALB} / \mathrm{c}$ mice inoculated with $\mathrm{CVB} 3$ to induce myocarditis with Phyllaemblicin B every day, significantly decreased virus titers in the heart and activities of $\mathrm{LDH}$ and $\mathrm{CK}$ in serum from the CVB3-induced myocarditic mice in comparison with those of the infected controls. In addition, damage to the myocardium was relieved, that is, the area of necrosis and inflammatory infiltrates of cardiac muscles were much lower in the treated groups. These results indicate that the presence of Phyllaemblicin B protects myocardial cells against the harmful effects of CVB3 and maintains the levels of 
associated enzymes at normal values.

Apoptotic events occur frequently during CVB3 infection under in vitro as well as in vivo conditions. Cardiomyocyte apoptosis has been previously shown to be important for both viral replication and virus-induced cardiac pathology after CVB3 infection (Martin et al. 2007; Gebhard et al. 1998). A recent study demonstrated that apoptosis was one detail of CVB3-induced pathogenesis. Apoptosis in picornavirus-infected cells may be a process triggered or accelerated by the virus to facilitate viral progeny release. Activation of the apoptotic machinery has been demonstrated in HeLa cells following CVB3 infection (Carthy et al. 1998). The mitochondria-mediated pathway is commonly believed to be associated with apoptosis induced by CVB3. In this pathway, cytochrome c release from mitochondria triggers the activation of caspases (Li et al. 1998). Further studies demonstrated that in addition to caspase-3 activation, multiple members of the caspase family were activated or degraded during CVB3 infection in HeLa cells and in murine atrial cardiomyocytes (Carthy et al. 2003). Bcl-2 is an inhibitor of the mitochondrial apoptosis pathway. This antiapoptotic molecule acts to inhibit the release of cytochrome c thereby blocking caspase activation and the apoptotic process (Kluck et al. 1997). Heat shock protein 75 (Hsp75/Grp75/mortalin/TRAP1) is a member of the HSP70 chaperone family, which is targeted to mitochondria. Overexpression of Hsp75 improved mitochondrial function and protected cells from apoptosis (Xu et al. 2009; Masuda et al. 2004, Ruiz-Romero et al. 2009).

In the present study, apoptosis was detected by a FACS assay. The rate of apoptosis in cells treated with Phyllaemblicin B was significantly lower than that in infected controls, suggesting that Phyllaemblicin B can inhibit apoptosis induced by CVB3. Proteins from 
treated and untreated groups were identified and analyzed using a proteomics approach based on two-dimensional DIGE and MALDI-TOF/TOF mass spectrometry. Treatment with Phyllaemblicin B resulted in upregulated expression of three proteins related to apoptosis: glutathione peroxidase 1-isoform 1 (GPX1), succinate dehydrogenase (ubiquinone) flavoprotein subunit-mitochondrial (SDHA), and heat shock protein 75 kDa-mitochondrial precursor (TRAP1). Gpx1, the major isoform of glutathione peroxidase, is present in both mitochondria and the cytosol (Esworthy et al. 1997). Gpx1 mediates mitochondrial protection and suppresses apoptosis progression. Overexpression of Gpx 1 in the heart attenuates cardiac dysfunction and improves mitochondrial complex respiration activity (Gao et al. 2008). SDHA prevents cell death and decreases nuclear degradation, mitochondrial disruption, membrane permeability, and caspase activation (Laguna et al. 2006). Meanwhile, increased expression of TRAP1 inhibits apoptosis induced by CVB3. These results indicate that the antiviral effects of Phyllaemblicin B are due to suppression of viral-induced apoptosis.

Moreover, caspase-3 and bcl-2 were analyzed for their respective gene and protein expression levels. Quantitative real-time RT-PCR and western blot analyses were performed in vitro on HeLa cells. Additionally, murine heart tissues were analyzed using immunohistochemistry to determine the expression of the two apoptosis-related proteins in vivo. We present results showing that the expression of caspase- 3 at the gene and protein levels is much lower in vitro and in vivo in the Phyllaemblicin B-treated groups. Meanwhile, the expression of bcl-2 was much higher in the treated groups. Taken together, these data suggest that Phyllaemblicin B can significantly suppress virus-induced apoptosis. 
Taken together, the present study the first time to demonstrate that Phyllaemblicin B has potent activity to inhibiting of CVB3 replication and CVB3-induced apoptosis in vitro and in vivo, and significantly inhibits CVB3-induced myocarditis, suggested that Phyllaemblicin B is a potential therapeutic agent against CVB3 infection and associated viral myocarditis.

\section{Acknowledgements}

This study was supported by the Joint Funds of National Science Foundation of China (U0632010), the State Key Laboratory of Phytochemistry and Plant Resources in West China, Chinese Academy of Sciences (P2008-KF07, O807E21211) and "211 grant of MOE".

\section{Reference}

Kuhl U., Pauschinger M., Noutsias M., Seeberq B., Bock T., Lassner D., Poller W., Kandolf R., Schultheiss H.P., 2005. High prevalence of viral genomes and multiple viral infections in the myocardium of adults with "idiopathic" left ventricular dysfunction. Circulation. 111, 887-893.

Chow L.H., Beisel K.W., McManus B.M., 1992. Enteroviral infection of mice with severe combined immunodeficiency. Evidence of direct viral pathogenesis of myocardial injury. Lab Invest. 66, 24-31.

McManus B.M., Chow L.H., Wilson J.E., Anderson D.R., Gulizia J.M., Gauntt C.J., Klingel K.E., Beisel K.W., Kandolf R., 1993. Direct myocardial injury by enterovirus: a central role in the evolution of murine myocarditis. Clin Immunol Immunopathol. 68, 159-169.

Huber S.A., Budd R.C., Rossner K., Newell M.K., 1999. Apoptosis in coxsackievirus 
B3-induced myocarditis and dilated cardiomyopathy. Ann NY Acad Sci. 887, 181-190. Henke A., Huber S., Stelzner A., Whitton J.L., 1995. The role of CD8+ T lymphocytes in coxsackievirus B3-induced myocarditis. J Virol. 69, 6720-6728.

Antoniak S., Boltzen U., Riad A., Kallwellis-Opara A., Rohde M., Dorner A., Tschope C., Noutsias M., Pauschinger M., Schultheiss H.P., Rauch U., 2008. Viral myocarditis and coagulopathy: Increased tissue factor expression and plasma thrombogenicity. J Mol Cell Cardiol. 45, 118-126.

Kerr J.F., Wyllie A.H., Currie A.R., 1972. Apoptosis: a basic biological phenomenon with wide-ranging implications in tissue kinetics. Br J Cancer. 26, 239-257.

Feuer R., Mena I., Pagarigan R.R., Harkins S., Hassett D.E., Whitton J.L., 2003. Coxsackievirus B3 and the neonatal CNS: the roles of stem cells, developing neurons, and apoptosis in infection, viral dissemination, and disease. Am J Pathol. 163, $1379-1393$.

Saraste A., Arola A., Vuorinen T., Kyto V., Kallajoki M., Pulkki K., Voipio-Pulkki L.M., Hyypia T., 2003. Cardiomyocyte apoptosis in experimental coxsackievirus B3 myocarditis. Cardiovasc Pathol. 12, 255-262.

Yuan J.P., Zhao W., Wang H.T., Wu K.Y., Li T., Guo X.K., Tong S.Q., 2003. Coxsackievirus B3- induced apoptosis and caspase-3. Cell Res. 13, 203-209.

Carthy C.M., Granville D.J., Watson K.A., Anderson D.R., Wilson J.E., Yang D., Hunt D.W., McManus B.M., 1998. Caspase activation and specific cleavage of substrates after coxsackievirus B3-induced cytopathic effect in HeLa cells. J Virol. 72, 7669-7675. Cunningham K.A., Chapman N.M., Carson S.D., 2003. Caspase-3 activation and ERK phosphorylation during CVB3 infection of cells: influence of the coxsackievirus and 
adenovirus receptor and engineered variants. Virus Res. 92, 179-186.

Martin U., Jarasch N., Nestler M., Rassmann A., Munder T., Seitz S., Zell R., Wutzler P., Henke A., 2007. Antiviral effects of pan-caspase inhibitors on the replication of coxsackievirus B3. Apoptosis. 12, 525-533.

Carthy C.M., Yanagawa B., Luo H., Granville D.J., Yang D., Cheung P., Cheung C., Esfandiarei M., Rudin C.M., Thompson C.B., Hunt D.W., McManus B.M., 2003. Bcl-2 and $\mathrm{Bcl}-\mathrm{xL}$ overexpression inhibits cytochrome c release, activation of multiple caspases, and virus release following coxsackievirus B3 infection. Virology. 313, 147-157.

Si X., Luo H., Morgan A., Zhang J., Wong J., Yuan J., Esfandiarei M., Gao G., Cheung C., McManus B.M., 2005. Stress-activated protein kinases are involved in coxsackievirus B3 viral progeny release. J Virol. 79, 13875-13881.

Zhang Y.J., Abe T., Tanaka T., Yang C.R., Kouno I., 2001. Phyllanemblinins A-F, New Ellagitannins from Phyllanthus emblica. J Nat Prod. 64, 1527-1532.

Xia Q., Xiao P., Wan L., Kong J., 1997. Ethnopharmacology of Phyllanthus emblica L. Zhongguo Zhong Yao Za Zhi. 22, 515-8, 525, 574.

Zhang Y.J., Tanaka T., Iwamoto Y., Yang C.R., Kouno I., 2000. Novel Norsesquiterpenoids from the Roots of Phyllanthus emblica. J Nat Prod. 63, 1507-1510. Mosmann T., 1983. Rapid colorimetric assay for cellular growth and survival: application to proliferation and cytotoxicity assays. J Immunol Methods. 65, 55-63.

Livak K.J., Schmittgen T.D., 2001. Analysis of relative gene expression data using real-time quantitative PCR and the 2(-Delta Delta C(T)) Method. Methods. 25, 402-408. Cihakova D., Rose N.R., 2008. Pathogenesis of myocarditis and dilated cardiomyopathy. Adv Immunol. 99, 95-114. 
Kearney M.T., Cotton J.M., Richardson P.J., Shah A.M., 2001. Viral myocarditis and dilated cardiomyopathy: mechanisms, manifestations, and management. Postgrad Med J. 77, 4-10.

Brunetti L., DeSantis E.R., 2008. Treatment of viral myocarditis caused by coxsackievirus B. Am J Health Syst Pharm. 65, 132-137.

Zhu H., Zhang Y., Ye G., Li Z., Zhou P., Huang C., 2009. In vivo and in vitro antiviral activities of calycosin-7-O-beta-D-glucopyranoside against coxsackie virus B3. Biol Pharm Bull. 32, 68-73.

Wang H., Ding Y., Zhou J., Sun X., Wang S., 2009. The in vitro and in vivo antiviral effects of salidroside from Rhodiola rosea L. against coxsackievirus B3. Phytomedicine. $16,146-155$.

Su M., Li Y., Leung K.T., Cen Y., Li T., Chen R., Ooi V.E., 2006. Antiviral activity and constituent of Ardisia chinensis benth against coxsackie B3 virus. Phytother Res. 20, 634-639.

Gebhard J.R., Perry C.M., Harkins S., Lane T., Mena I., Asensio V.C., Campbell I.L., Whitton J.L., 1998. Coxsackievirus B3-induced myocarditis: perforin exacerbates disease, but plays no detectable role in virus clearance. Am J Pathol. 153, 417-428. Carthy C.M., Granville D.J., Watson K.A., Anderson D.R., Wilson J.E., Yang D., Hunt D.W., McManus B.M., 1998. Caspase activation and specific cleavage of substrates after coxsackievirus B3-induced cytopathic effect in HeLa cells. J. Virol. 72, 7669-7675. Li H., Zhu H., Xu C.J., Yuan J., 1998. Cleavage of BID by caspase 8 mediates the mitochondrial damage in the Fas pathway of apoptosis. Cell. 94, 491-501. Kluck R.M., Bossy-Wetzel E., Green D.R., Newmeyer D.D., 1997. The release of 
cytochrome c from mitochondria: a primary site for Bcl-2 regulation of apoptosis. Science. $275,1132-1136$.

Xu L., Voloboueva L.A., Ouyang Y., Emery J.F., Giffard R.G., 2009. Overexpression of mitochondrial Hsp70/Hsp75 in rat brain protects mitochondria, reduces oxidative stress, and protects from focal ischemia. J Cereb Blood Flow Metab. 29, 365-374.

Masuda Y., Shima G., Aiuchi T., Horie M., Hori K., Nakajo S., Kajimoto S., Shibayama-Imazu T., Nakaya K., 2004. Involvement of tumor necrosis factor receptor-associated protein 1 (TRAP1) in apoptosis induced by beta-hydroxyisovalerylshikonin. J Biol Chem. 279, 42503-42515.

Ruiz-Romero C., Calamia V., Mateos J., Carreira V., Martinez-Gomariz M., Fernandez M., Blanco F.J., 2009. Mitochondrial dysregulation of osteoarthritic human articular chondrocytes analyzed by proteomics: a decrease in mitochondrial superoxide dismutase points to a redox imbalance. Mol Cell Proteomics. 8, 172-189.

Esworthy R.S., Ho Y.S., Chu F.F., 1997. The Gpx1 gene encodes mitochondrial glutathione peroxidase in the mouse liver. Arch Biochem Biophys. 340, 59-63. Gao J., Xiong Y., Ho Y.S., Liu X., Chua C.C., Xu X., Wang H., Hamdy R., Chua B.H., 2008. Glutathione peroxidase 1-deficient mice are more susceptible to doxorubicin-induced cardiotoxicity. Biochim Biophys Acta. 1783, 2020-2029. Laguna R.K., Creasey E.A., Li Z., Valtz N., Isberg R.R., 2006. A Legionella pneumophila-translocated substrate that is required for growth within macrophages and protection from host cell death. Proc Natl Acad Sci U S A. 103, 18745-18750. 
Table 1

Inhibitory effects of Phyllaemblicin B on infected HeLa cells.

\begin{tabular}{lccc}
\hline Drug & TC50 $(\mu \mathrm{g} / \mathrm{mL})$ & $\mathrm{IC} 50(\mu \mathrm{g} / \mathrm{mL})$ & $\mathrm{TI}$ \\
\hline Phyllaemblicin B & $50.30 \pm 1.59$ & $7.75 \pm 0.15$ & $6.49 \pm 0.09$ \\
Ribavirin & $700 \pm 19$ & $182 \pm 7.81$ & $3.85 \pm 0.11$ \\
\hline
\end{tabular}

TC50 is the concentration of the drug showing $50 \%$ cytotoxicity. IC50 is the concentration of drug required to inhibit $50 \%$ of the viral cytopathic effect. TI is the therapeutic index $=$ TC50/IC50.

Table 2

Up-regulated proteins in Phyllaemblicin B-treated group $(25 \mu \mathrm{g} / \mathrm{mL})$.

Protein nameAccession No.Protein scorePI/Mr (Da) Function

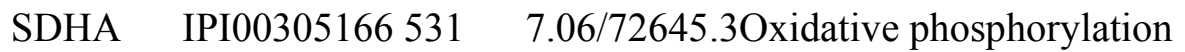

GPX1 IPI00293975 $250 \quad 6.15 / 22027.2$ Peroxidase

TRAP1 IPI00030275 $543 \quad 8.3 / 80059.7$ HSP 90 family chaperone 
Fig. 1. The chemical structure of Phyllaemblicin B.

Fig. 2. Annexin V/PI analysis of apoptosis. (A) HeLa cells infected with CVB3 were incubated with $25 \mu \mathrm{g} / \mathrm{mL}$ Phyllaemblicin B for $24 \mathrm{~h}$, after which the cells were harvested and analyzed by FACS. Phyllaemblicin B decreased the proportion of apoptotic cells. (B) The apoptosis rates of cells. (a) Normal control, (b) infected control, (c) infected with CVB3 and treated with Phyllaemblicin B $(25 \mu \mathrm{g} / \mathrm{mL})$, (d) infected with CVB3 and treated with Ribavirin $(125 \mu \mathrm{g} / \mathrm{mL}) .{ }^{*} \mathrm{p}<0.05$, compared with the infected control.

Fig. 3. 2-DE maps of treated and control groups. (A) Comparison of the protein expression patterns between control and Phyllaemblicin B-treated $(25 \mu \mathrm{g} / \mathrm{mL}) \mathrm{HeLa}$ cells. Circles highlight areas where significant differences in protein expression are present. (B) Upregulation of three proteins in the Phyllaemblicin B-treated group. (a) TRAP1,(b) SDHA and (c) GPX1.

Fig. 4. The mRNA expression of caspase- 3 and bcl-2 in treated and control groups. Caspase-3 and bcl-2 mRNA levels expressed as a fraction of the reference gene GAPDH. (a) Infected control and (b) Phyllaemblicin B-treated $(25 \mu \mathrm{g} / \mathrm{mL}),{ }^{*} \mathrm{p}<0.01$, compared with infected control.

Fig. 5. Detection of caspase-3 and bcl-2 expression in Phyllaemblicin B-treated $(25 \mu \mathrm{g} / \mathrm{mL})$ and control groups by Western blot analysis. $\beta$-Actin was examined to normalize any differences in loading.

Fig. 6. Effects of Phyllaemblicin B on the activities of LDH and CK in infected mouse serum eight days post-infection. (a) Normal control, (b) infected control, (c) Ribavirin (125mgkg $\left.{ }^{-1} \mathrm{~d}^{-1}\right)$, (d) Phyllaemblicin B (12 $\left.\mathrm{mgkg}^{-1} \mathrm{~d}^{-1}\right)$, (e) Phyllaemblicin B (8mg kg $\left.\mathrm{d}^{-1}\right)$, (f) Phyllaemblicin $\mathrm{B}\left(4 \mathrm{mg} \mathrm{kg}^{-1} \mathrm{~d}^{-1}\right),{ }^{*} \mathrm{p}<0.05$, compared with infected controls.

Fig. 7. Effects of Phyllaemblicin $B$ on virus titers in BALB/c mice infected with CVB3 at eight days post-infection. (a) Normal control, (b) infected control, (c) Ribavirin (125 mgkg $\left.{ }^{-1} \mathrm{~d}^{-1}\right)$, (d) Phyllaemblicin B (12 $\left.\mathrm{mgkg}^{-1} \mathrm{~d}^{-1}\right)$, (e) Phyllaemblicin B (8mgkg $\left.{ }^{-1} \mathrm{~d}^{-1}\right)$ and (f) Phyllaemblicin B $\left(4 \mathrm{mg} \mathrm{kg}^{-1} \mathrm{~d}^{-1}\right),{ }^{*} \mathrm{p}<0.05$, compared with infected controls.

Fig. 8. HE-stained sections of hearts from different groups. (A) Normal control, (B) infected control, mononuclear cell inflammation and necrotic cardiomyocyte site were indicated by a small black arrow. (C) Ribavirin (125 $\left.\mathrm{mgkg}^{-1} \mathrm{~d}^{-1}\right)$, (D) Phyllaemblicin B $\left(12 \mathrm{mgkg}^{-1} \mathrm{~d}^{-1}\right)$, (E) Phyllaemblicin B $\left(8 \mathrm{mg} \mathrm{kg}^{-1} \mathrm{~d}^{-1}\right)$, and (F) Phyllaemblicin B $\left(4 \mathrm{mgkg}^{-1}\right.$ $\left.\mathrm{d}^{-1}\right)$.

Fig. 9. Detection of apoptotic cardiomyocytes with the TUNEL assay. (A) Normal control, (B) infected control, apoptosis cell was indicated by a small white arrow. (C) Phyllaemblicin B $\left(12 \mathrm{mgkg}^{-1} \mathrm{~d}^{-1}\right)$. 
Fig. 10. Histological appearance of Coxsackie virus B3-induced murine myocarditis. (A and A') normal control, (B and B') infected control, (C and C') Phyllaemblicin B $\left(12 \mathrm{mgkg}^{-1} \mathrm{~d}^{-1}\right)$. 
Fig. 1

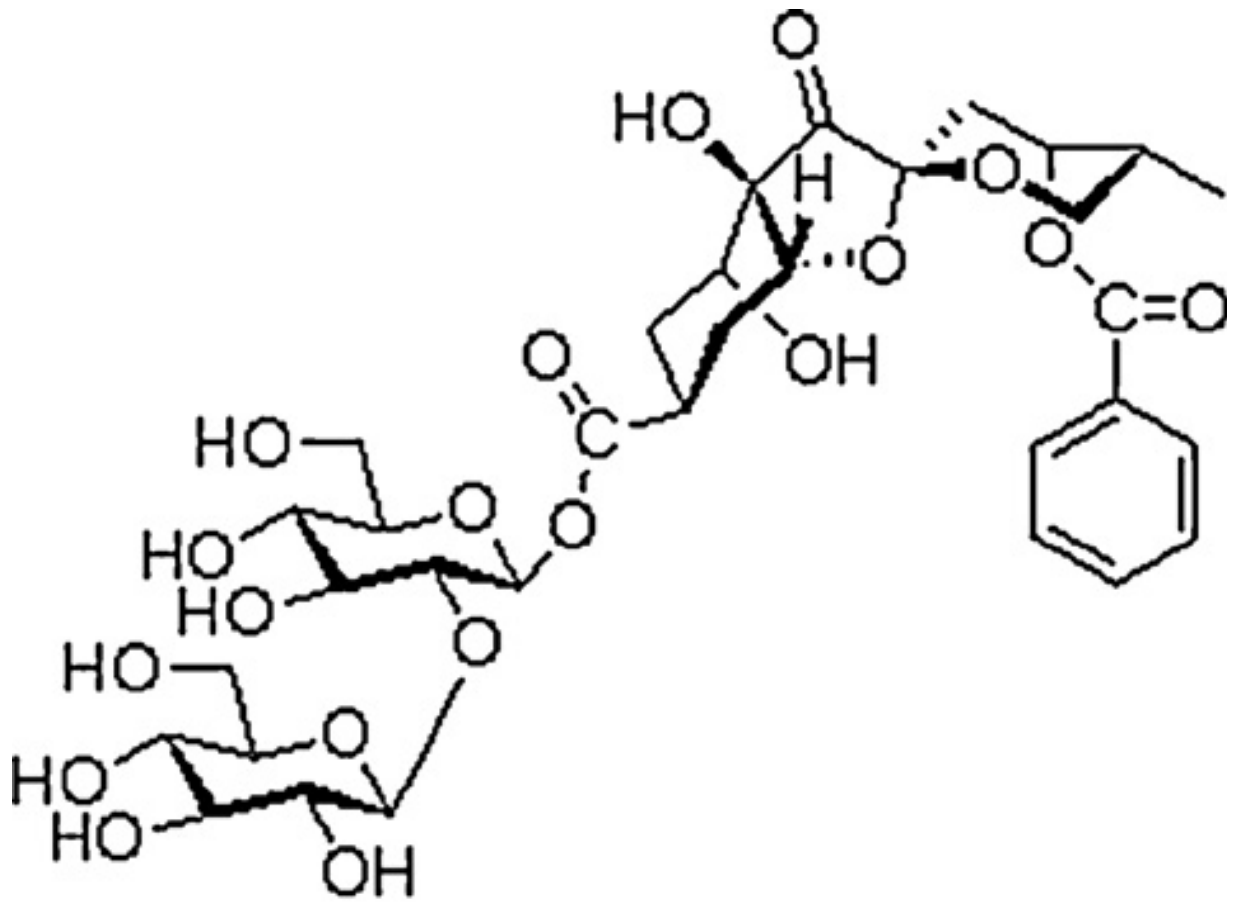

Phyllaemblicin B 
Fig. 2
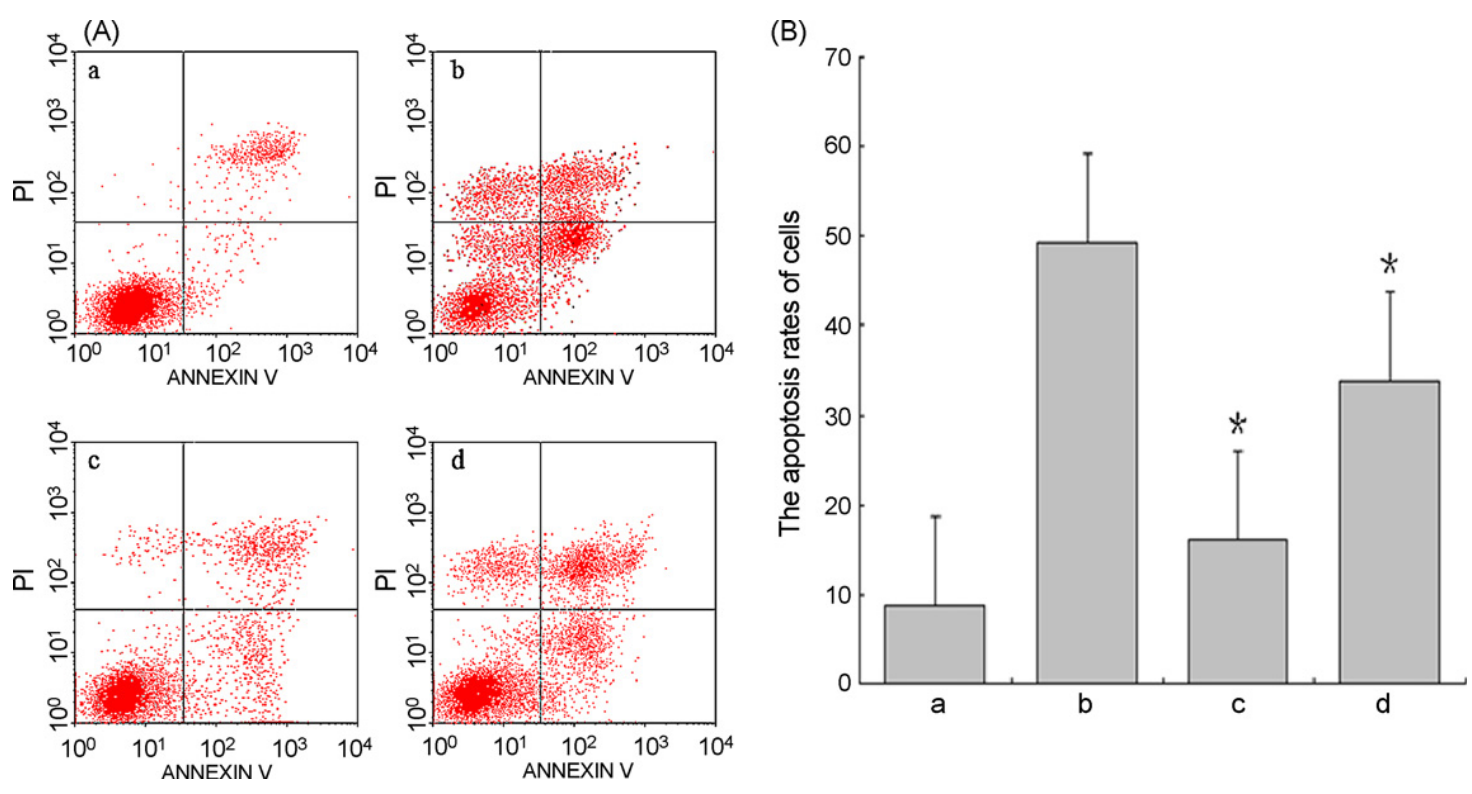
Fig. 3
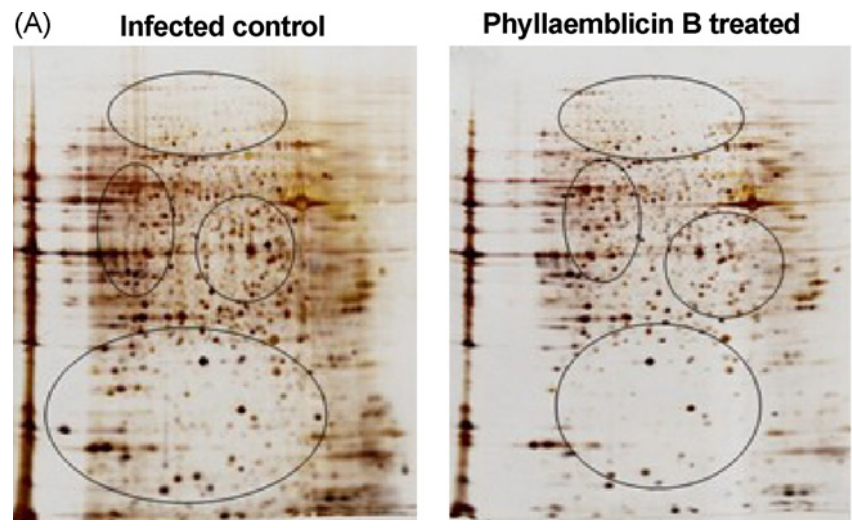

(B) Infected control

Phyllaemblicin B treated
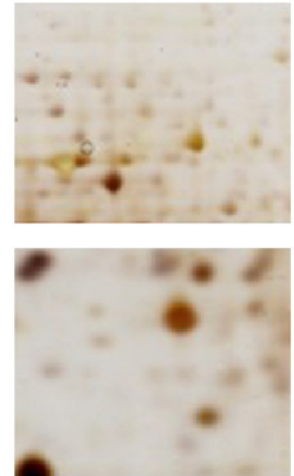
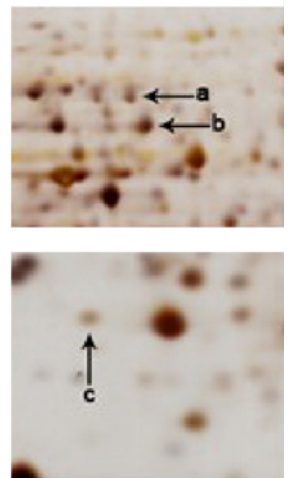
Fig. 4
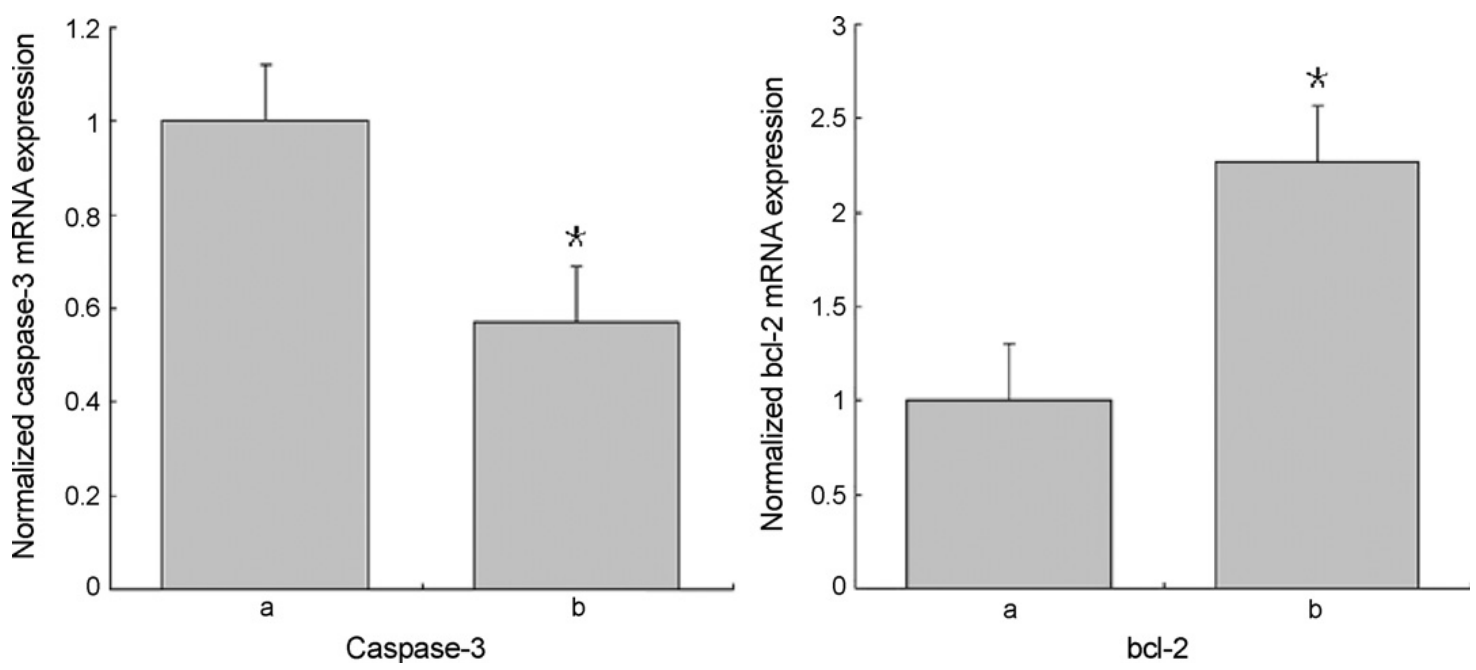
Fig. 5

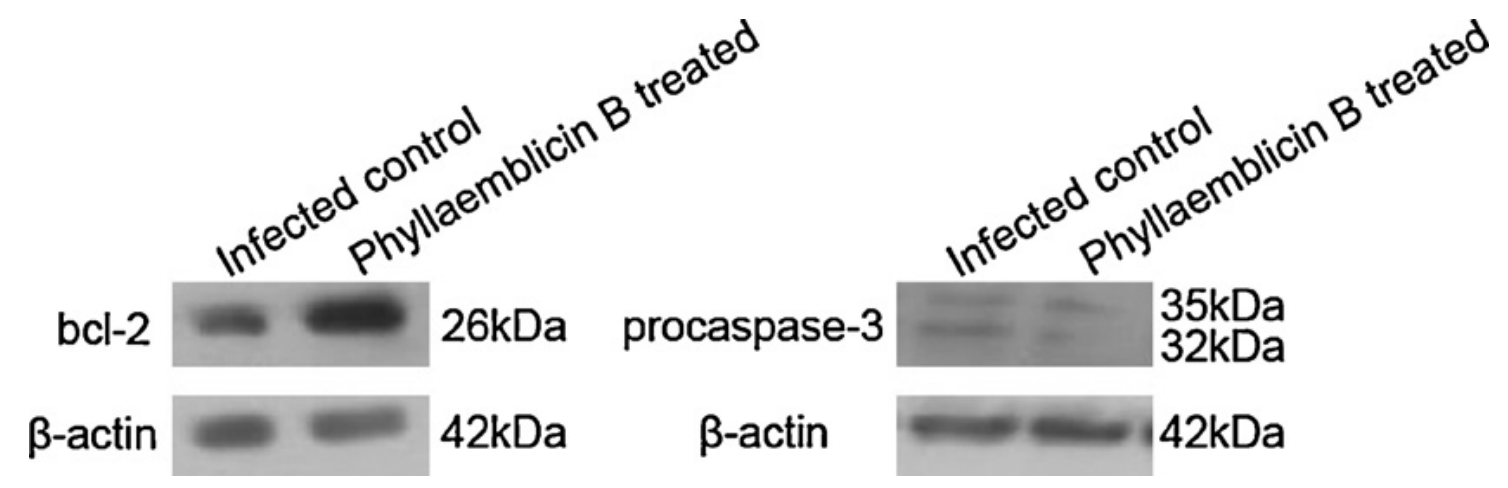


Fig. 6
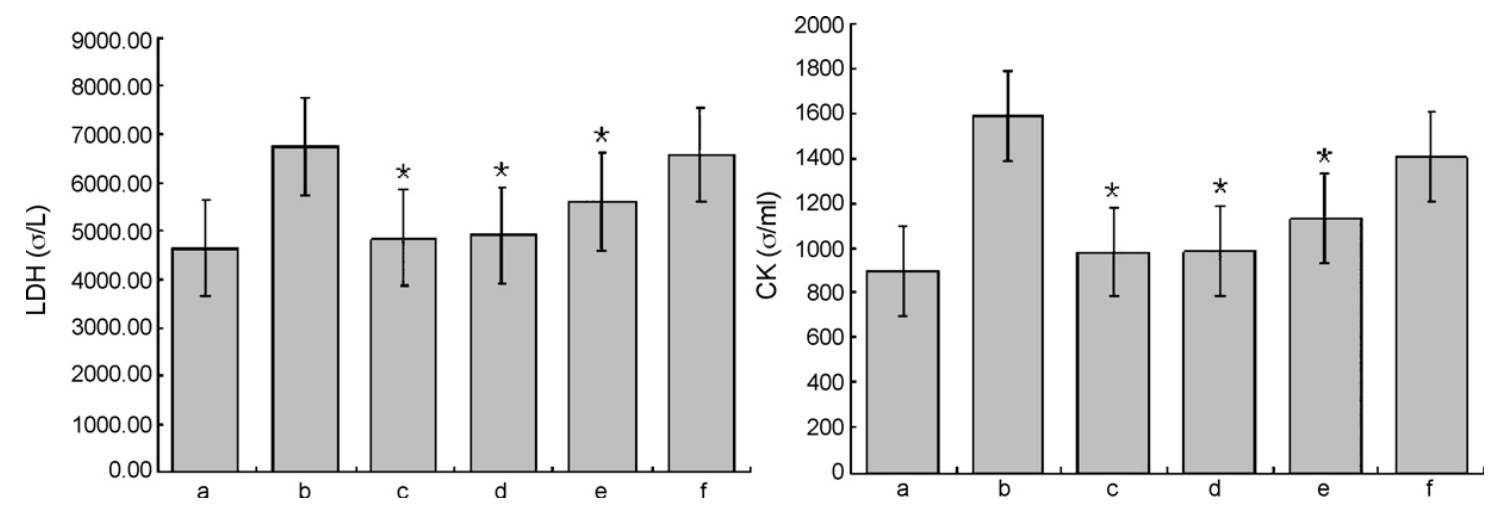
Fig. 7

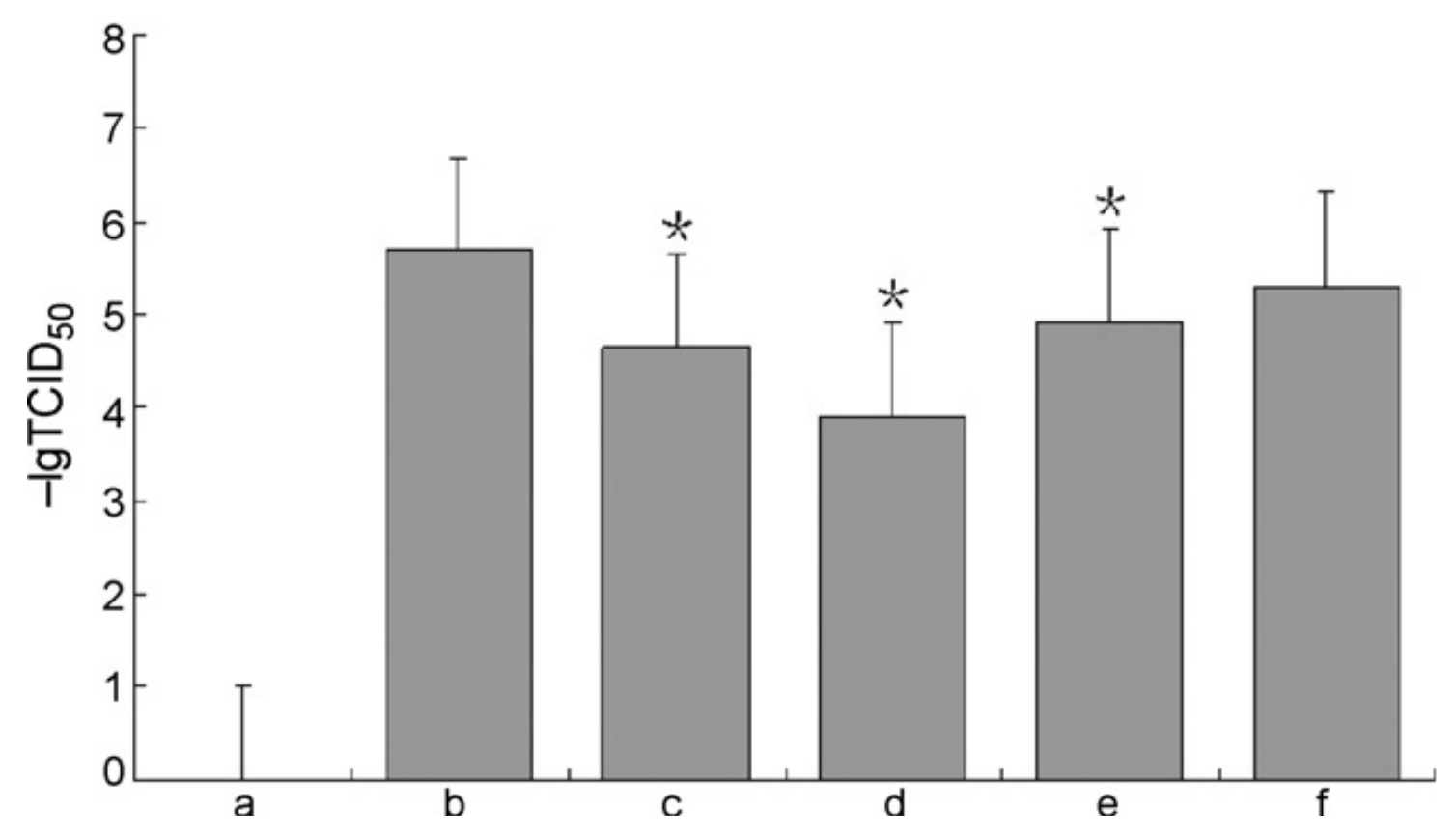


Fig. 8
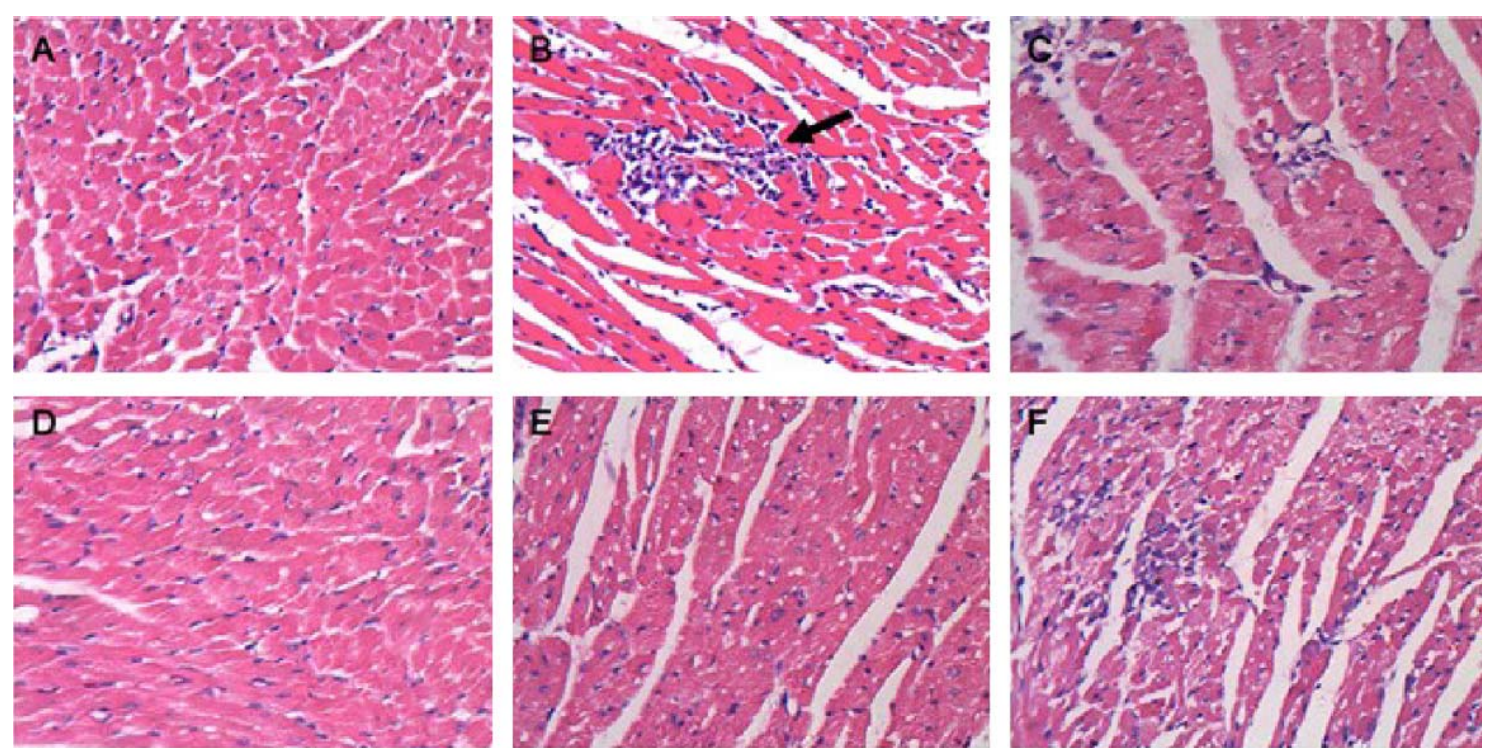
Fig. 9
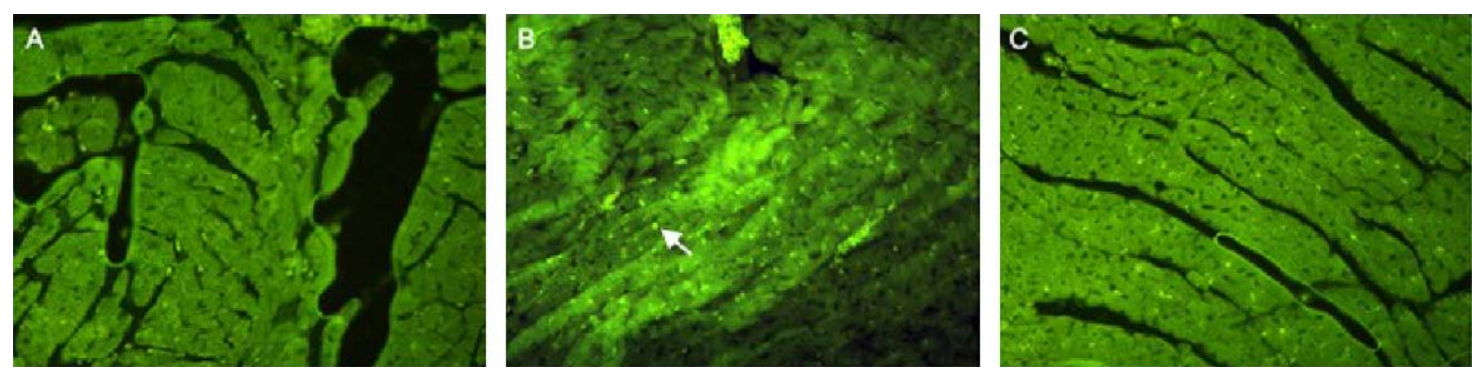
Fig. 10

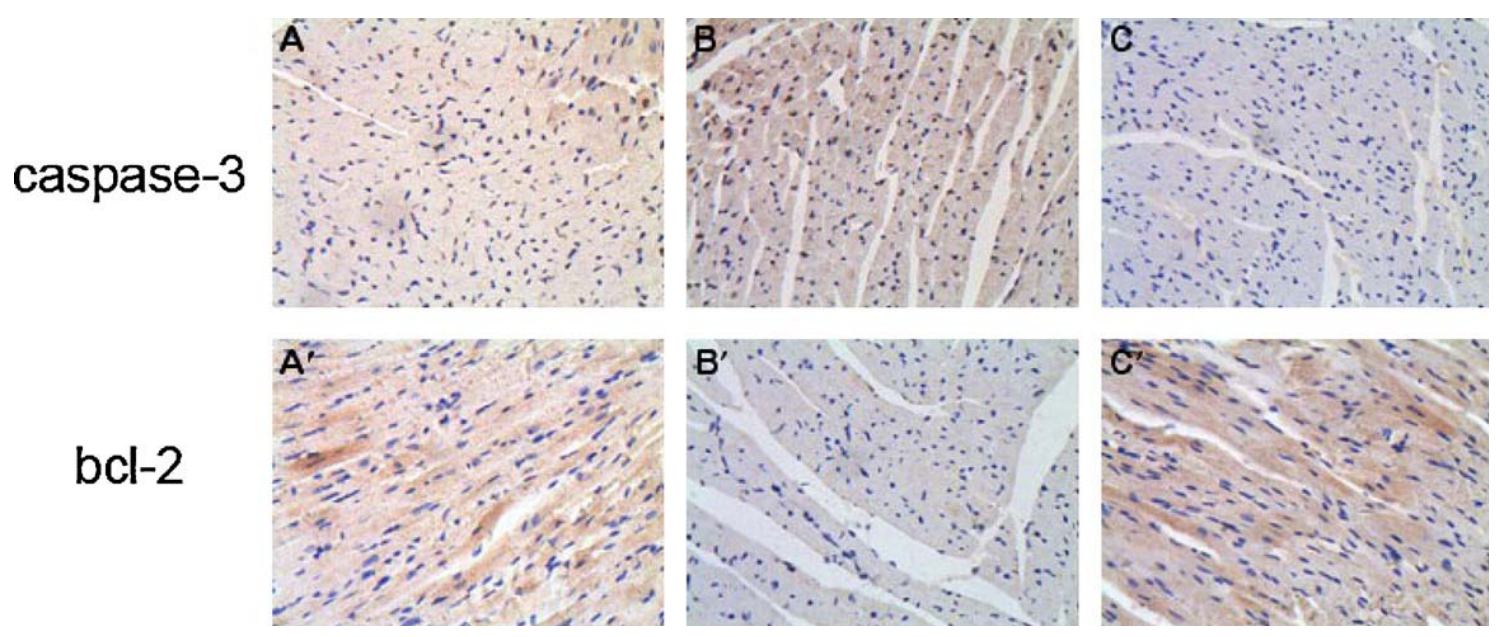

